\title{
ERRATUM
}

\section{Impact of the use of an alcohol-based hand sanitizer in the home on reduction in probability of infection by respiratory and enteric viruses - ERRATUM}

\section{A. H. TAMIMI, S. MAXWELL, S. L. EDMONDS AND C. P. GERBA}

doi: http://dx.doi.org/10.1017/S0950268815000035. Published online: 31 March 2015

In the above-mentioned article [1] panel $(c)$ of Figure 1 is missing. The complete Figure is given below.
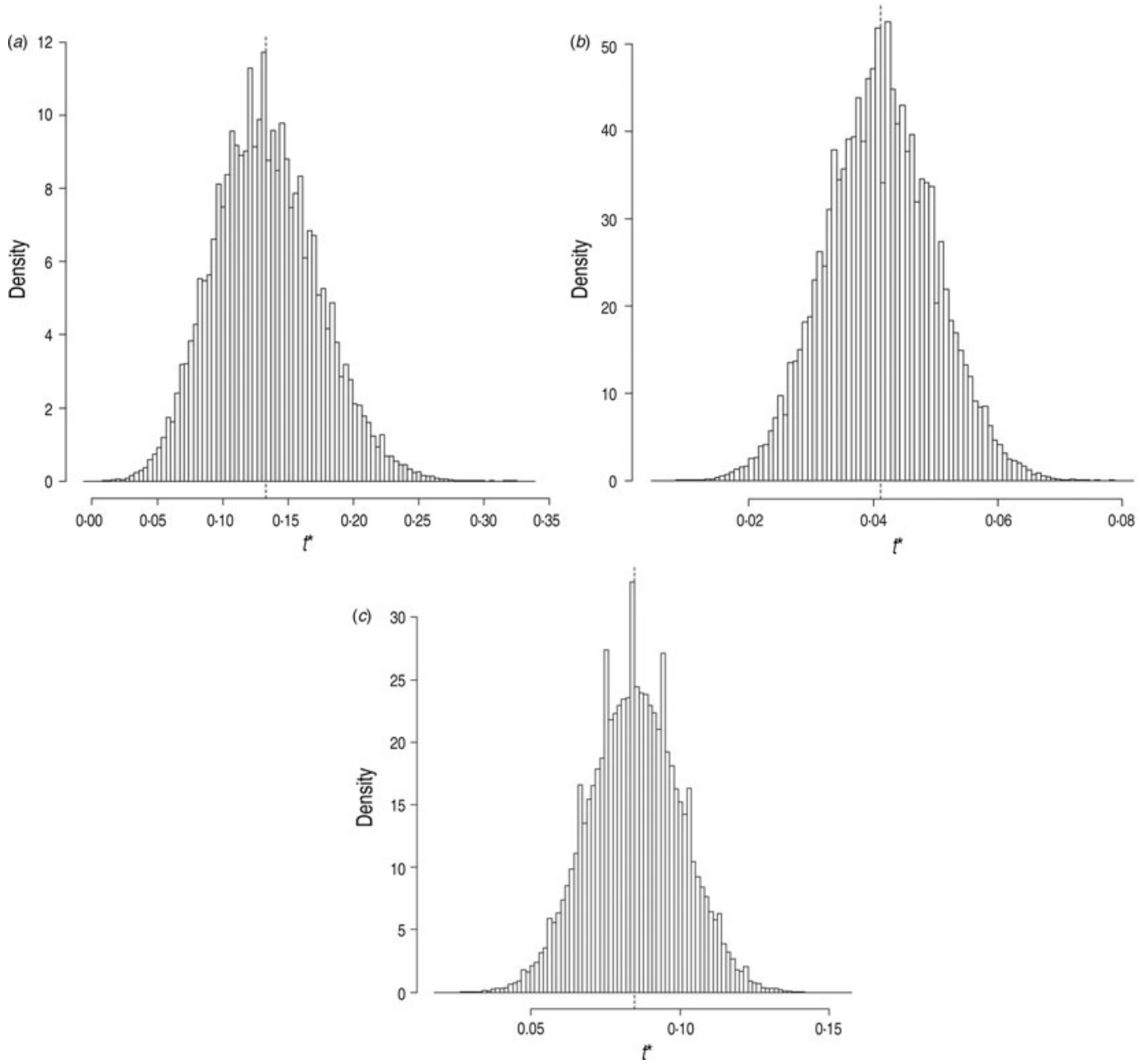

Fig. 1. Generated distributions for face contact frequency using bootstrapping. (a) Hand-to-mouth contacts/min; $(b)$ hand-to-eye contacts/min; $(c)$ hand-to-nose contacts/min.

\section{REFERENCE}

1. Tamimi AH, et al. Impact of the use of an alcohol-based hand sanitizer in the home on reduction in probability of infection by respiratory and enteric viruses. Epidemiology and Infection. doi:10.1017/S0950268815000035. Published online 31 March 2015. 